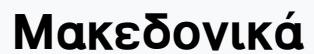

Tóp. 5, Ap. 1 (1963)

MAKG_ONIKA

EYTTPAMMA IIEPIOAIKON

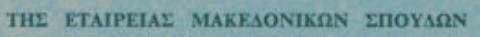

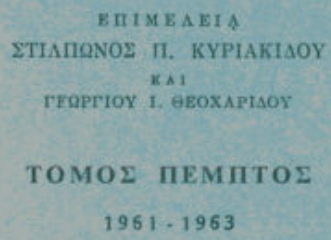

1961.1963

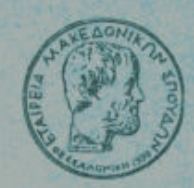

RN $\theta$ E $\Sigma$ ХA ONIKH

19.63

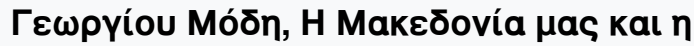



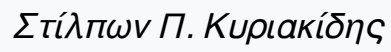

doi: $10.12681 /$ makedonika.862

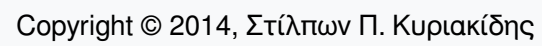

\section{(c) (1)(2)}

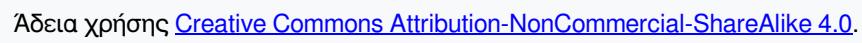

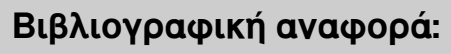


5(1), 584-585. https://doi.org/10.12681/makedonika.862 


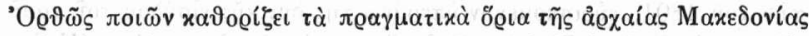





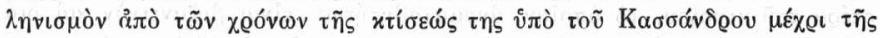

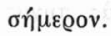

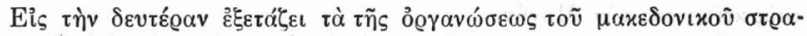

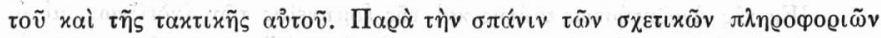

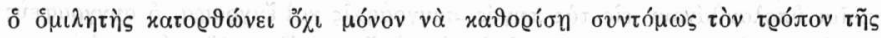

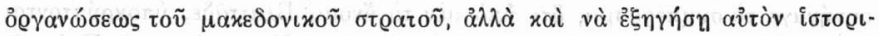

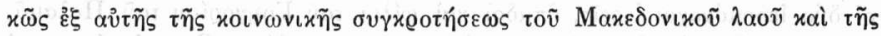

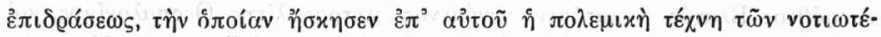

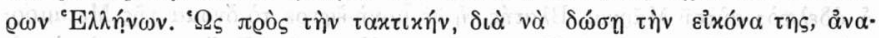

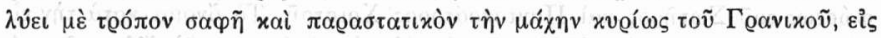

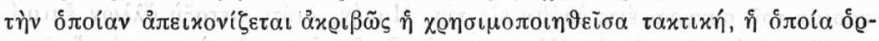

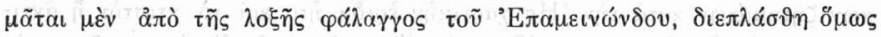

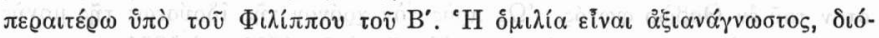

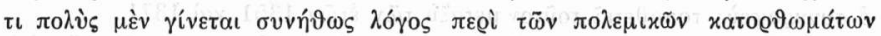

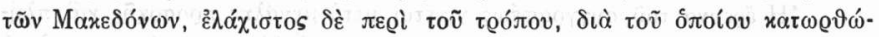

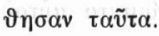

$\Sigma T I A \Pi \Omega N$ ก. KYPIAKIAH

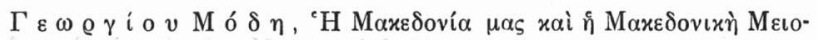

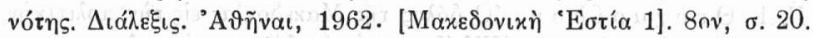

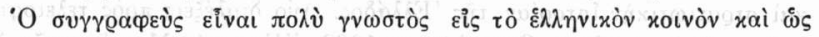

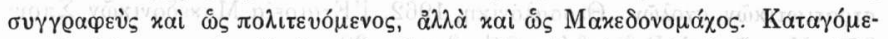

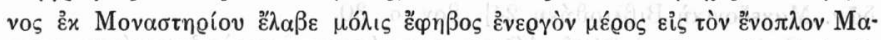
$x \varepsilon \delta \delta$ เ



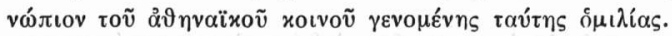

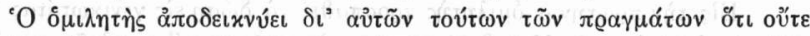

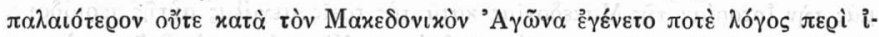

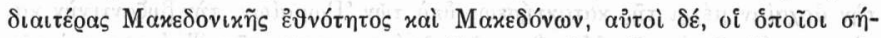

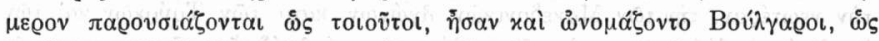

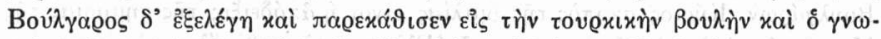

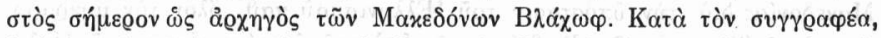

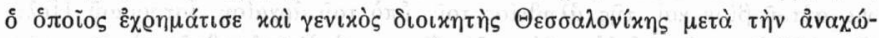

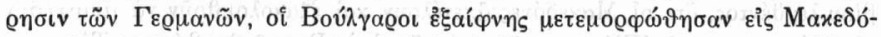

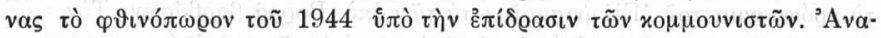



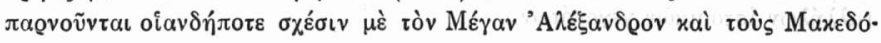




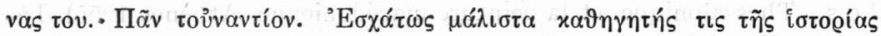

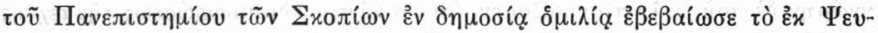

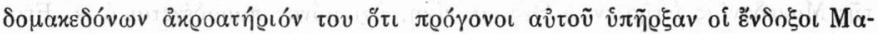

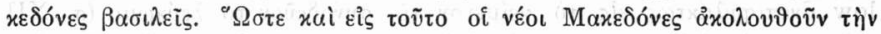

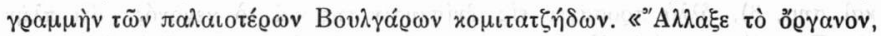

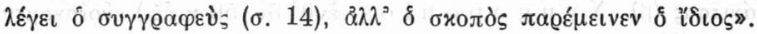

'A

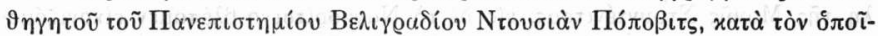

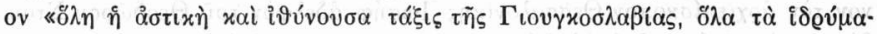

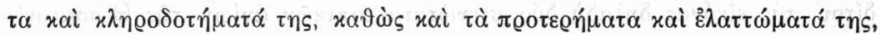



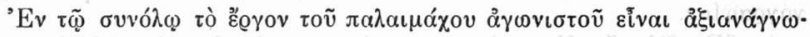



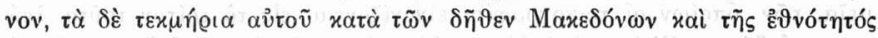



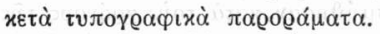

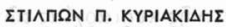

G. Millet, La peinture du moyen âge en Yougoslavie (Serbie, Macédoine, Monténégro). Fascicule III. Album présentè par A. F r o.

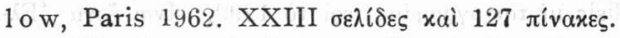

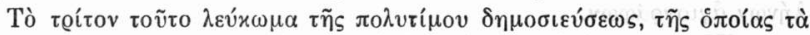





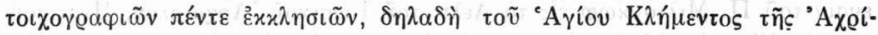

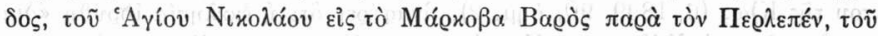

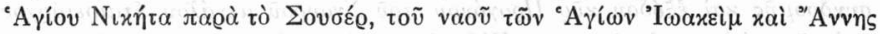

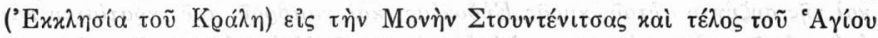

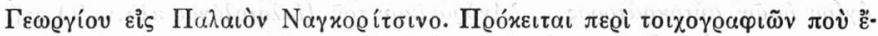



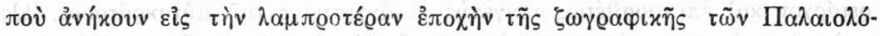

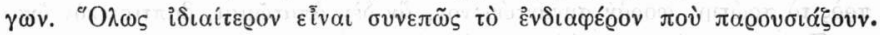

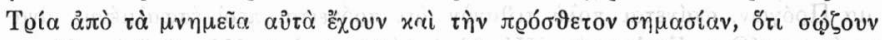

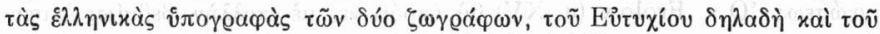

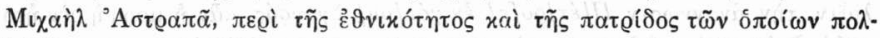

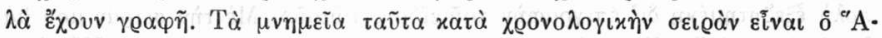

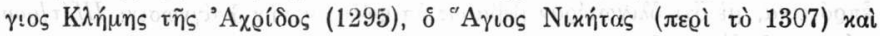

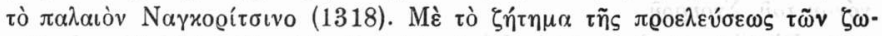

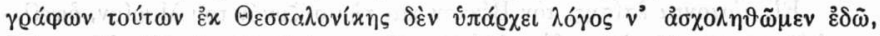

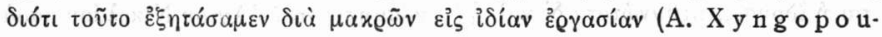

